\title{
MANAGERIAL TOOLS FOR SUSTAINABLE DEVELOPMENT
}

\section{Mirela Danubianu ${ }^{1}$, Cristian Teodorescu ${ }^{2}$}

Keywords: Managerial tools, strategic planning, sustenability

Abstract. - In the last decade, complex statistical studies related to top managerial tools proven to impact the most the performances of business companies show the following (changing) hierarchy (excerpts):

- Strategic Planning;

- Customer Relationship Management;

- $\quad$ Employee Engagement Survey;

- $\quad$ Corporate Social Responsibility;

- Balanced Scorecard.

These tools are, practically, unknown to the majority of companies with Romanian capital. This cannot go on like that. The main argument comes from the conditions in which these companies act, from increasing challenges from similar EU companies, from globalization and from increased awareness for sustainable development. The paper tries to identify a common mainframe for implementing such tools. Specific aspects are also given as examples.

Main conclusions are:

1. Even in a general mainframe, there is no unique approach applicable to all companies;

2. Involvement of top managers is essential;

3. The appointed implementation team is multidisciplinary in every case (technical experts, economists, environmentalists, mathematicians, IT professionals, etc.). Their legitimacy gives consistence and coherence to the implementing process;

4. An external, neutral facilitator is a must. He is the guide, the referee, the one that deals with possible disputes and divergences in the team;

5. All new managerial tools must be based on what companies already have;

This paper is the first in a series dedicated to the subject and comes as a side result of the PAZEWAIA Project, financed by Innovation Norway, project currently active in the North-East Development Region of Romania.

\footnotetext{
1 "Ştefancel Mare" University-Suceava, mdanub@eed.usv.ro

${ }^{2}$ GEC-Bucovina, Suceava, christit@gmail.com
} 


\section{Managerial tools for the new Millenium}

The growing concern about surviving globalization, resource scarcity and increasing public interest and awareness led companies to look for and implement advanced managerial tools.

The driving forces for this process are (Bain\&Co, 2015):

- Seeking growth and accelerating innovation in a changing business climate. The urge to innovate and change is believed more important for a given company than cost reduction or marketing.

- Cost and excessive complexity are a worrying hindrance to company development. The advent of more and more complex techniques, such as: nanotechnologies, robotics, cloud technology, advanced biotechnologies, or new materials puts managers in front of unknown and yet unexplored fields.

- The conversion to digital environment definitely assures growth and innovation, enable managers to master complexity, and cope with threats and risks. New technologies, such as Data Mining and Big Data (Danubianu et al, 2014) have proven their efficiency in processing companies' "historical" records and in identifying trends, correlations and interactions never thought to exist.

- Understanding and cooperating with all stakeholders. Managers go beyond company's fences, discuss and interact with their neighbours, with communities, the decision process becomes everybody's business, at least in the search and assessment of various alternatives for development, in building trust and reassure communities of company's concern and responsibility for environment and societal problems (BASF, 2015).

Though the tools in the list above come from the $20^{\text {th }}$ Century, they became extremely active in the last 10-15 years at the top of managerial practice. There are some of them that continuously dispute their place in the Top- 5 of best managerial tools at global level. A selection (Bain\&Co, 2015) that includes also the authors' contribution follows:

1. Customer Relationship Management-CRM

2. Employee Engagement Survey - EES

3. Benchmarking

4. Balanced Scorecard - BSC

5. Corporate Social Responsibility - CSR

6. Outsourcing

7. Mission and Vision Statements

8. Supply Chain Management

The paper will try to identify common features, a common framework for implementation of such tools. Number three in the list, though not present in the original Bain's survey is believed to become more and more relevant once there are international standards in the field already active (ISO 26000, 2010). 
The present paper represents the first part of a series. It is connected to the Partnerships with Zero-Waste Industrial Activities (PAZEWAIA, 2015) Project financed by the Norwegian Government through Innovation Norway. During the PAZEWAIA project implementation, local managers were informed and helped to access and use advanced managerial tools.

\section{A common ground for implementation}

Though different as they seem, the managerial tools in the above list prove very similar in the approach used for their implementation. A series of tasks connect them, though the content and intimate details of these tasks differ from tool to tool. This common structure is analyzed in the subsequent paragraphs.

The main steps and tasks for the implementation of the above mentioned tools, detailed here are all inspired by the sustainability paradigm present in all recent EU documents (see e.g., EU-CSR Strategy, 2011; Europe 2020, 2015) and company's commitment to the triple bottom line of sustainable development (economic, environmental, social). They are presented as they have been used in specific cases for Romanian companies.

Task 0:Initial organizing of the managerial tool implementation, This step comprises the essential commitment of the company's top management (expressed in a formal document, be it for the Customer Relationship Management, Corporate Social Responsibility or Balanced Scorecard system of strategic management), the nominalization of the implementation team and its responsible person, the acceptance of a neutral, external facilitator/advisor, the setup of a Project Advisory Board (PAB), plus the set of formal documents enabling the Team to access all information across the company, the procedures for working and reporting progress to the top managers.

The facilitator will act as a guide, referee and moderator for cases when disputes arise. The team is multidisciplinary (technical experts, economists, environmentalists, marketing specialists, public relation experts, computer wizards, etc.).

The employees must realize at this very early phase that the top management commitment is genuine and that implementing a new specific managerial tool will not end with a document to be shelved and forgotten. Here the role of an external facilitator proves essential in order to explain and to exemplify, to smooth the collaboration among all team members and resolve potential conflicts. For all the team members it is important to understand that they are working together as equal partners, each coming with his own expertise and background, forgetting hierarchical differences. Ideas and opinions must be encouraged to flow free. Critical analysis will come later. 
Task 1: Initial audit and assessment. A presentation of what a specific managerial tool is and what should be the outcomes of the implementing process is made by the external facilitator. SWOT analyses, specially tailored questionnaires and interviews are then conducted by the external facilitator. They would lead to assess where exactly the company is in the field covered by the specific tool (not where the top managers believe the company is!). In order to access all relevant and sensitive aspects in the Company, questionnaires and filled-in SWOT forms are forwarded to the external facilitator unsigned and interviews are conducted separately (and observing full confidentiality) with all managers and other stakeholders in the Company (e.g., head of employees' union) as well with selected stakeholders. The conclusions of this task are presented to the Team. Differences between the existing situation and the expected final result of the implementation are underlined.

A list of issues, classified along their relevance for the company and along the capacity of the company to sort them out in order to swiftly implement a given managerial tool is set up at this stage. The implementation team starts now working on a company policy in the field. This is a short, synthetic, mobilizing document endorsed by all employees and posted across the company premises. The process is recurrent and interactive and it should not be hurried as the Team is learning only little by little what the specific managerial tool is. A final version of the Policy would come at the very end of the implementation process, after a trial \& error process and confrontation with new aspects, with Board members wishes, etc.

Task 2: Identifying and engaging stakeholders. A list of potential stakeholders and their place and inter-relations is presented in Fig. 1 (Werther and Chandler, 2004).

From case to case, more or less categories of stakeholders will be included in the implementation process. When dealing with CSR, CRM practically all stakeholders in Fig. 1 should be addressed. When implementing BSC, the number of involved stakeholders is limited. As can be seen from the illustration, inner categories of stakeholders are present in outer categories as well, meaning, e.g., that employees may occasionally become customers or are currently members of the communities, while still maintaining their connections and interests in the company business. On the other hand, though members of the communities or administrative authorities are also potential customers of the company, they have no economic interest or relationship with the company and are no formal part what so ever in that company.

The framework in Fig. 1 must be regarded in the broader framework of current trend of globalization where accelerated technology development creates new contexts. It means that individual companies have responsibilities not only against their customers or employees but must pro-actively think to how their business 
could affect environmental and social issues at local, regional, global level. At this point, the implementation team must realize the real challenges put to the Company and why openness and cooperation among all team members and with all stakeholders is in their interest and essential for the future.

If stakeholders are to be included in the implementation, it must be done as early as possible in the process, but not before all the team members has established their consensual shared point of view about what the tool they are working on really is, what are the expectations. A workshop gathering all identified stakeholders should be organized as early as possible, but only when the Team members could answer all potential uneasy questions and could pertinently comment upon all remarks coming from the participants.

\begin{tabular}{l} 
Societal Stakeholders: \\
Governmental, Administration and other relevant Authorities (e.g., regulators, \\
enforcing entities) \\
Environment and environmental authorities \\
NGOs \\
Communities and individuals \\
International Organizations (Human Rights, Environment, etc.) \\
Media \\
$\qquad \begin{array}{l}\text { Business Stakeholders: } \\
\text { Members of the value chain (suppliers, distributors, } \\
\text { customers) } \\
\text { Financing authorities (banks, creditors, EU agencies) } \\
\text { Industry Associations (e.g., in the field of chemistry, } \\
\text { pulp and paper, cement, etc.) }\end{array}$ \\
\begin{tabular}{|l|l|} 
Organizational \\
Stakeholders: \\
Employees \\
Unions \\
Management \\
Stockholders
\end{tabular} \\
\hline
\end{tabular}

Figure 1.Categories of Company's stakeholders.

At the company initiative, a Project Advisory Board (PAB) should be organized at this stage and its first meeting can now be organized. The PAB is not compulsory but, as it includes respected members in the company, retired persons having a proven expertise and positive impact upon team members, even representatives of company's stakeholders, the $\mathrm{PAB}$ is a recognized guide, a 
legitimate actor that can help the implementation team and reduce entropy generation during the implementing process. The role of PAB is:

a. To guide the implementation team by evaluating and censoring its actions, legitimate them so that they are tailored exactly upon what the company \& its stakeholders, as a whole body, believe is best for everyone;

b. To enable straightforward interaction with all stakeholders, NGOs (usually very active and vocal) with the general public and media

c. To add their expertize to company's experts, by covering fields up to now not considered in the decision making process of the company (environmental, cultural, historical, particular social aspects).

Engaging stakeholders triggers new processes that the Company must learn how to manage and could, in principle, span over a continuum of interaction that reflects the degree of influence stakeholders are allowed to have in decision making. At one end, businesses might simply inform stakeholders of their plans. At the other, stakeholders can be deeply involved in the decision making process.

The relationship among company and stakeholders will change in time. As a first step, both parts must make efforts to accept and understand each other as partners and establish a mode of communication.

Task 3: Develop commitments. Each managerial tool comes with its specific list of commitments, directions of actions or programs for substantiating the implementation process. As an illustration, in the case of implementing CSR at company's level, the list (non-exhaustive) of possible commitments is briefly presented in the subsequent paragraphs:

a. Cause promotion. The company frees resources in order to increase its visibility in supporting a cause;

b. Cause Related Marketing. For a limited period of time, the company donates in favour and benefit of an entity (e.g., $2 \%$ of sales of a specific product go to the provide equipment for specific hospitals)

c. Corporate Social Marketing. e.g., the company fights against family violence, tries to help people with disabilities, etc. This contributes to the change of the public behaviour.

d. Corporate Philanthropy. The company directly contribute to support an urgent case (e.g., saving a community affected by a catastrophe, etc.).

e. Community Volunteering. The Company encourages its employees to take part in supporting a community or a cause (employees and equipment, wearing company's logo go cleaning a National Reservation, go building houses for poorer families, etc.).

In any specific managerial tool case, not all such directions are of the same importance and come with the same benefits for the company in the short, medium or long term. In addition, company's resources for such programs are very limited 
so they must be spent to get the most benefit of it. A Multi-Criteria-DecisionMaking Matrix may be used to classify the company's actions. Stakeholders and company representatives are requested to fill in a template like in Table 1 in order to establish the priority of actions. The Table illustrates a simple situation where only the five lines of actions and only four stakeholders are considered. Each stakeholder is asked to give scores from 1 (less relevant in the context and at the moment of decision) to 5 (most relevant in the same context). Each row must contain a " 1 " and a " 5 ". The final scores are obtained, for example, by adding up individual scores. In the present case, the "Social Marketing" gets the highest score, so the company must start working on this issue, not forgetting the other two lines of action having top scores of " 12 ".

Table 1. Form to be completed for multi-criteria decision making.

\begin{tabular}{cccccc}
\hline & $\begin{array}{c}\text { Cause } \\
\text { Promotion }\end{array}$ & $\begin{array}{c}\text { Cause } \\
\text { Marketing }\end{array}$ & $\begin{array}{c}\text { Social } \\
\text { Marketing }\end{array}$ & Philantropy & Volunteering \\
\hline Managers & 2 & 1 & 5 & 3 & 3 \\
Employees & 1 & 5 & 4 & 2 & 1 \\
Customers & 1 & 4 & 3 & 5 & 2 \\
Community & 4 & 2 & 1 & 4 & 5 \\
SCORE & $\mathbf{8}$ & $\mathbf{1 2}$ & $\mathbf{1 3}$ & $\mathbf{1 2}$ & $\mathbf{1 1}$ \\
\hline
\end{tabular}

Such decision-making processes should become common for the company's managers. A very important intangible by-result is that, in the process, company managers (and stakeholders, if there is the case) learn to work together, cooperate, exchange views, and understand each other.

The decision approach can become more complex by allocating a relevance index to each stakeholder (e.g., distributors or suppliers may not be as important as communities or Environment). And instead of simply adding up scores attributed by all stakeholders, a more elaborated Spearman rank correlation coefficient procedure could lead to the final consolidated scores. The implementation team will feel, in time, the need for a more sophisticated approach and it must be encouraged by the facilitator to identify and apply such approaches.

It is important to note that the above procedure must be doubled by a very strong ethical component and a wish to do-good for company, its employees, its stakeholders and stockholders before pondering what could be the outcome for the business. It is the managers' choice to advertise their actions as loudly and cynically as possibly or let the actions speak for themselves. An educated public would be more sensitive to the later approach.

Task 4: Put the managerial tools in practice. Each line of action mentioned above can be implemented at tactical level, using many more detailed activities.

Examples:

- Corporate Governance 
- Cleaner Production, ZERO-Waste

- Circular Economy and Industrial Symbiosis

- Environmentally friendly products

- Educating communities

- Involving schools

- No bribery, zero corruption

- Value chain observing the triple bottom line of sustainability

- Creating action programs (together with communities), with given timeframes, deadlines, resource allocated, and responsibility attributed which is the most important part, with a set of Key Performance Indicators (KPI) assessing the progress toward the full implementation of a given tool (Stiglitz, 2008).

- Motivational actions

- Reporting along recognized frameworks (e.g., FTSE4Good, 2015), etc.

These are tactical actions that should help the rapid implementation of a given managerial tool. These actions and the associated KPI should be based on what already exists and operational in a given Company. The middle managers will better understand and apply the new tool if they meet something familiar in the process.

\section{New tools and the company strategy}

Putting Action Plans in practice may follow a well-known procedure similar to the Deming Cycle (Plan - Do - Check - Act) in the way that a detailed plan will be followed by practical actions, by a feedback connection to monitor progress and results and by a procedure to correct and improve the implementation process. It is important to underline that the Action Plans should involve all relevant stakeholders, be they only inside of the organization or not. This can be done by creating mixed task teams or working groups.

The monitoring and reporting tasks are also the attributes of all stakeholders involved (communication, dialogue are therefore essential). Sharing responsibility will alleviate the burden of the company and could add resources to the process, creating in the same time a cooperative environment for future programs.

Task 5: Integrate the new tool in the company strategy. A way to do it is presented in Fig. 2.

Alignment to the existing strategy should be done along the triple bottom line of sustainable development.

Starting from the well-known Kaplan and Norton's Balanced Scorecard system of strategic management (BSC, 2015), the implementation team should identify new / updated strategic objectives and insert them in the company's strategy. 
The Strategic Map of the company, organized along the classical four perspectives of the Balanced Scorecard is divided along the three pillars of sustainability (economic, environment, social).

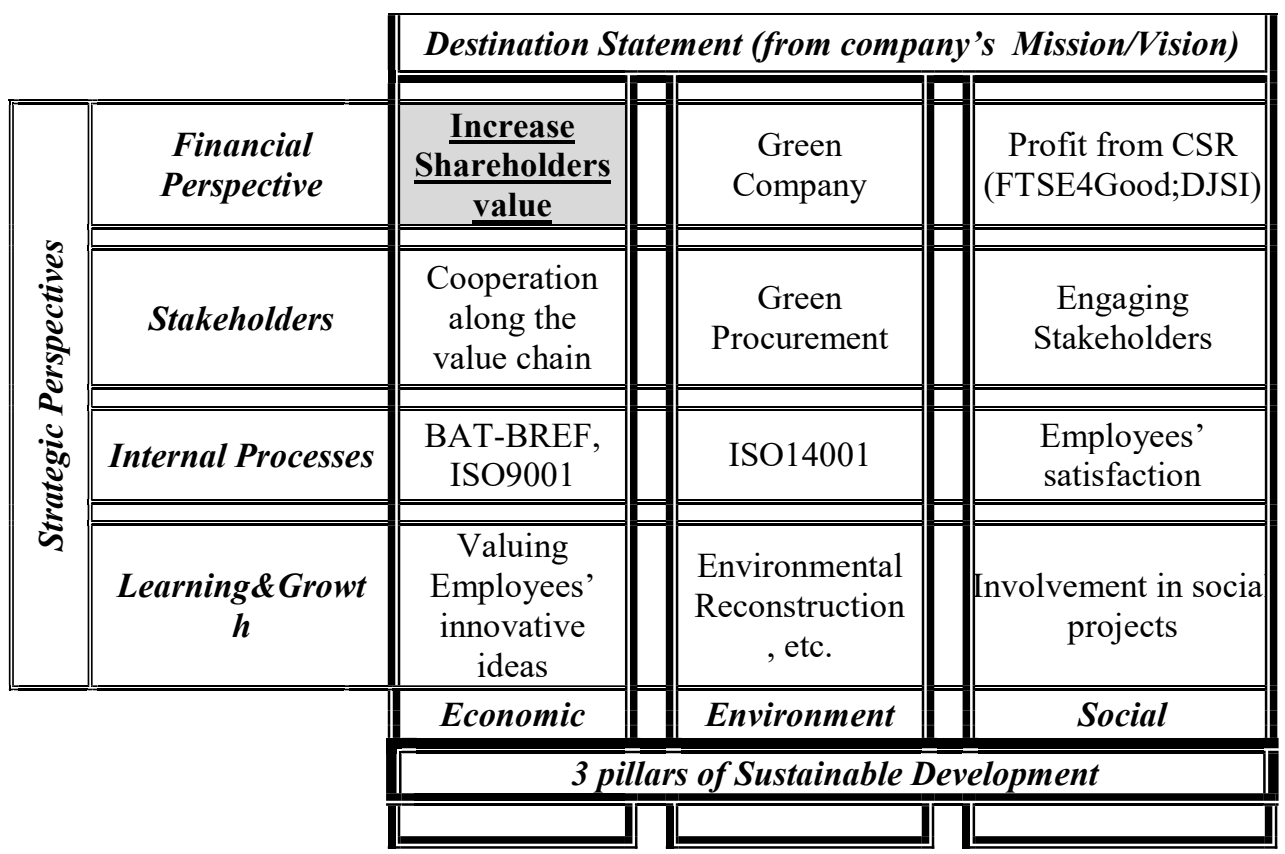

Figure 2. Company's Strategic Map where additional objectives coming with the aid of the newly implemented tool have to be inserted.

Organizing the strategic objectives in a Map like that in Fig. 2, have the following advantages:

- The Strategic Map is a public document in which stakeholders will recognize their initiatives and the commitment of the company's managers to put them into practice;

- It is a powerful communication vector for the public. It shows that the company is equally concerned by all aspects of sustainable development

- During the implementation phase, once a strategic objective is not fulfilled, such a strategic map could show what the consequences are. Those responsible for not doing their job as expected will support all the consequences.

- Starting from this map, each objective is detailed (Action Plans, resources, Key Performance Indicators and associated targets, monitoring and reporting procedures, etc.). 


\section{Conclusions}

At the end of the implementation process, the company has got the following:

- an expert team that knows in detail a given managerial tool, has tested it and proven its efficiency;

- a complete set of Programs, Actions, KPI, etc., ready to help the implementation of a given managerial tool or replicated in order to implement a new one;

- a strategy that already includes the contribution of the new tool;

- a management system that includes state-of-the-art tools;

- a vast experience in cooperating with stakeholders.

Future papers in the series will go in detail with specific managerial tool, implemented in Romanian companies.

\section{References}

Bain\&Co (2015), http://www.bain.com/publications/articles/management-tools-andtrends-2015.aspx , accessed Sep 20, 2015;

BASF (2015), BASF Neighbor-to-Neighbor event promotes 'Responsible Care', http://www.thenewsherald.com/articles/2015/10/28/news/doc562a38827ba934894009 10.txt, accessed Oct 21, 2015;

BSC (2015), http://balancedscorecard.org/, accessed Oct 12, 2015

Danubianu, Mirela, et al (2014), Data-mining - a valuable managerial tool for improving power plants efficiency, Present Environment and Sustainable Development, 8(2), 205-216;

EU-CSR Strategy (2011), COM(2011)-681: A renewed EU strategy 2011-14 for Corporate Social Responsibility, European Commission, http://eurlex.europa.eu/legal-content/EN/TXT/PDF/?uri=CELEX:52011DC0681\&from=EN , retrieved, October 2, 2015;

Europe 2020 (2015), http://ec.europa.eu/europe2020/index_en.htm , accessed Sep 30, 2015.

FTSE4Good (2015) Index Series, available at http://www.ftse.com/products/indices/FTSE4Good accessed , accessed on Oct 6, 2015 ;

ISO26000 (2010), Guidelines for Social Responsibility, http://www.cnis.gov.cn/wzgg/201405/P020140512224950899020.pdf, retrieved Oct 6,2015

PAZEWAIA (2015), News about the Project is available at http://www.idnorway.com/2014/09/successful-pazewaia-workshop-in-suceava-22-9-2014/ accessed Oct 15, 2015

Stiglitz, J. et al (2008), Commission On The Measurement Of Economic Performance And Social Progress, Commission on the Measurement of Economic Performance and Social Progress (CMEPSP), Issues paper 25/07/08-1;

Werther, W.B.Jr. and Chandler, D. (2006), Strategic Corporate Social Responsibility, Sage Publications, Thousand Oaks, California, United States 